\title{
Too Little Too Late: Effect of Poor Access to Biologics for Patients with Rheumatoid Arthritis
}

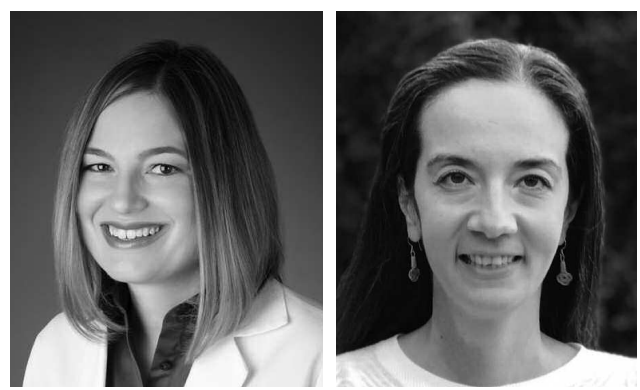

Biologic disease-modifying antirheumatic drugs (bDMARD), in particular anti-tumor necrosis factor (anti-TNF) medications, which were developed in the 1990s, have improved the radiographic and functional status of patients with rheumatoid arthritis (RA) ${ }^{1}$. It has been thought as a corollary that rates of joint replacement in patients with RA would decrease. Results in various national databases since the advent of biologic medications have been discrepant; for example, in a US cohort there was a decrease in arthroplasty in juvenile idiopathic arthritis, but not RA from 1991 to $2005^{2}$, whereas in Ireland the arthroplasty rate was halved from 1995 to $2010^{3}$. In Japan there was no change in the rate up to 2008, while in Sweden the hip arthroplasty rate decreased, but the knee rate did not ${ }^{4}$. Overall, however, the trend seems to be toward lower rates of arthroplasty in patients with RA.

An article in this issue of The Journal, by Stamp, et $a l^{5}$, provides an interesting analysis of the rates of joint replacement in New Zealand from 1999 to 2015 in both OA and RA since the advent of biologic medications. The results show that according to a New Zealand Joint Registry (1999-2015), while OA joint replacement rates for total knee replacement (TKR) and hip replacement (THR) increased, for patients with RA there was no decrease in the rate of TKR and THR.

How should one interpret these data of no decrease in the RA TKR and THR rates? One should look through the lens of the current situation in New Zealand regarding access to the biologics. Per the authors, biologics were not available in New Zealand until 2006, and even then only 1 was available. Contrast this to the situation of the United States, where there was biologic access nearly a decade earlier.

Further, the authors cite draconian eligibility criteria for biologics in New Zealand: patients need to not only fail triple therapy, but also have erosions on their radiographs. As a stark example, the rate of biologic use in this RA cohort undergoing arthroplasty was $<10 \%$; in a similar US-based cohort the rate was over $50 \%{ }^{6,7}$. Clearly the government policy has affected biologic access for patients with RA in New Zealand.

To demonstrate a contrast, other countries have far less stringent access criteria. These countries have shown better outcomes regarding decreased rates of arthroplasty. In Sweden, although failure of 2 traditional DMARD is recommended, rheumatologists are given discretion to use biological therapy ${ }^{8}$. In the United States, patients with RA typically must first fail methotrexate, but rheumatologists can use bDMARD as a first-line therapy in early and aggressive disease or in those with contraindications to use of traditional DMARD. In Japan, patients can also be prescribed bDMARD at the discretion of a rheumatologist if they fail traditional DMARD, a policy also far less stringent than the New Zealand criteria. England and Wales have criteria more similar to New Zealand regarding the prescription of biological agents - the patient must fail 2 traditional DMARD, and a state of severe disease is also required (28-joint Disease Activity Score > 5.1), but even these countries do not require erosions prior to biologic initiation $^{8}$.

This article raises a salient question on the international platform: what should inform a government's policy for access to biologics for patients with RA? Costs are invariably part and parcel of any discussion of access to biologics. A population-based analysis of indirect and direct costs attributable to RA in Sweden showed the total national burden of illness of 600 million euros in $2010^{9}$ (US\$708 million), and in the United States, it has been estimated at up to US $\$ 19.2$ billion ${ }^{10}$. A 2009 study by the National Audit Office in England estimated that RA costs the UK National Health Service $£ 560$ million annually, and puts the additional costs from absence from work and aspects of work-related disability at $£ 1.8$ billion a year ${ }^{11}$.

These tremendous costs of RA should not be surprising for rheumatologists, but the additional burden of joint replacements for patients with RA who have poor disease control can significantly compound these costs. Biologic

See Comparison of joint replacement in RA and OA, page 1823

Personal non-commercial use only. The Journal of Rheumatology Copyright (C) 2017. All rights reserved. 
agents, despite their costs, can lower the disease burden for society. This was shown in an analysis of the Swedish Rheumatology Registers, which demonstrated that TNF-inhibitor treatment was associated with an increase in quality-adjusted life years and an incremental cost compared to no biological treatment ${ }^{12}$.

According to the Global Burden of Disease 2010 study, RA was ranked as the 42nd-highest contributor to global disability, representing a modest global disability, but with severe consequences for the individuals affected ${ }^{13}$. The European League Against Rheumatism (EULAR) and American College of Rheumatology (ACR) recommend starting bDMARD immediately after diagnosis or after traditional DMARD failure. However, because of the high cost of biology therapies, many national guidelines remain far removed from the goals-based approach recommended by EULAR and ACR. Government policies and national guidelines should consider adopting the societal perspective on reimbursement, as in Sweden, which suggests that the availability of biologic agents may award longterm benefits to both patients with RA and to healthcare systems.

The advent of biosimilars opens a brave new world of opportunity to reduce the cost of access to biological DMARD $^{14}$. It is our hope that the data from the article by Stamp, et al will open the eyes not just in New Zealand of those who determine access rules for biologics, but also in countries around the world. It is clear from this article that access to biologics for patients with RA after the presence of erosions is too little too late.

BEVERLY K. JOHNSON, MD, MS, FACR, Assistant Professor of Medicine, Albert Einstein College of Medicine, Director of Rheumatology, Jacobi Medical Center and North Central Bronx (NCB) Hospital;

ASENA BAHÇE-ALTUNTAŞ, MD, FACR, Assistant Professor of Medicine, Albert Einstein College of Medicine, Director of the Joint Pain Clinic, Jacobi/NCB, New York, New York, USA.

Address correspondence to Dr. B.K. Johnson, Jacobi/NCB, Rheumatology, 1400 Pelham Parkway, South Building 1, Suite 306, New York, New York 10461, USA.E-mail: beverly.johnson06@gmail.com

\section{REFERENCES}

1. Pincus T, Sokka T, Kautiainen H. Patients seen for standard rheumatoid arthritis care have significantly better articular, radiographic, laboratory, and functional status in 2000 than in 1985. Arthritis Rheum 2005;52:1009-19.

2. Mertelsmann-Voss C, Lyman S, Pan TJ, Goodman SM, Figgie MP, Mandl LA. US trends in rates of arthroplasty for inflammatory arthritis including rheumatoid arthritis, juvenile idiopathic arthritis, and spondyloarthritis. Arthritis Rheumatol 2014;66:1432-9.

3. Harty L, O'Toole G, FitzGerald O. Profound reduction in hospital admissions and musculoskeletal surgical procedures for rheumatoid arthritis with concurrent changes in clinical practice (1995-2010). Rheumatol 2014;54:666-71.

4. Hekmat K, Jacobsson L, Nilsson J-Å, Petersson IF, Robertsson O, Garellick G, et al. Decrease in the incidence of total hip arthroplasties in patients with rheumatoid arthritis - results from a well defined population in south Sweden. Arthritis Res Ther 2011;13:R67

5. Stamp LK, Haslett J, Chapman P, O’Donnell J, Raja R, Rothwell A, et al. Rates of joint replacement surgery in New Zealand, 1999-2015: a comparison of rheumatoid arthritis and osteoarthritis. J Rheumatol 2017;44:1823-7.

6. Johnson BK, Goodman SM, Alexiades MM, Figgie MP, Demmer RT, Mandl LA. Patterns and associated risk of perioperative use of anti-tumor necrosis factor in patients with rheumatoid arthritis undergoing total knee replacement. J Rheumatol 2013;40:617-23.

7. Goodman SM, Ramsden-Stein DN, Huang WT, Zhu R, Figgie MP, Alexiades MM, et al. Patients with rheumatoid arthritis are more likely to have pain and poor function after total hip replacements than patients with osteoarthritis. J Rheumatol 2014;41:1774-80.

8. Hockley T, Costa-Font J. A common disease with uncommon treatment: European guideline variations and access to innovative therapies for rheumatoid arthritis. 2012. [Internet. Accessed October 10, 2017.] Available from: https://policy-centre.com/ wp-content/uploads/2017/04/RAGuidelines.pdf

9. Kalkan A, Hallert E, Bernfort L, Husberg M, Carlsson P. Costs of rheumatoid arthritis during the period 1990-2010: A register-based cost-of-illness study in Sweden. Rheumatol 2014;53:153-60.

10. Birnbaum H, Pike C, Kaufman R, Marynchenko M, Kidolezi Y, Cifaldi M. Societal cost of rheumatoid arthritis patients in the US. Curr Med Res Opin 2010;26:77-90.

11. UK National Audit Office. Services for people with rheumatoid arthritis. 2009. [Internet. Accessed October 10, 2017.] Available from: www.nao.org.uk/report/services-for-people-withrheumatoid-arthritis/

12. Lekander I, Borgström F, Lysholm J, van Vollenhoven RF, Lindblad $\mathrm{S}$, Geborek P, et al. The cost-effectiveness of TNF-inhibitors for the treatment of rheumatoid arthritis in Swedish clinical practice. Eur J Health Econ 2013;14:863-73.

13. Cross M, Smith E, Hoy D, Carmona L, Wolfe F, Vos T, et al. The global burden of rheumatoid arthritis: estimates from the Global Burden of Disease 2010 study. Ann Rheum Dis 2014;73:1316-22.

14. Dörner T, Strand V, Castañeda-Hernández G, Ferraccioli G, Isaacs JD, Kvien TK, et al. The role of biosimilars in the treatment of rheumatic diseases. Ann Rheum Dis 2013;72:322-8.

J Rheumatol 2017;44:1765-6; doi:10.3899/jrheum.171148 